Article

\title{
Amine-functionalized boehmite nanoparticle-supported molybdenum and vanadium complexes: Efficient catalysts for epoxidation of alkenes
}

\author{
Mahdi Mirzaee*, Bahram Bahramian, Marieh Mirebrahimi \\ Department of Chemistry, Shahrood University of Technology, Shahrood, Iran
}

\section{A R T I C L E I N F O}

Article history:

Received 26 March 2016

Accepted 30 April 2016

Published 5 August 2016

\section{Keywords:}

Boehmite nanoparticles

Heterogeneous catalysts

Hexa-carbonyl molybdenum

Oxo-sulfate vanadium

Epoxidation

\section{Introduction}

Epoxides are well known as one of the most valuable intermediates for the production of commercially important chemicals such as polyglycols, polyamides, polyurethanes and many other polymers, pharmaceuticals, food additives, epoxy paints, dye-stuffs, flavour and fragrance compounds [1-8], and non-toxic PVC-plasticizers and stabilizers [8-10]. They are also valuable additives to lubricants and adhesives $[8,11,12]$.

In addition to conventional Mo complexes, several other soluble complexes of $\mathrm{V}, \mathrm{W}, \mathrm{Re}, \mathrm{Mn}, \mathrm{Ru}, \mathrm{Co}, \mathrm{Fe}$, and Ti have been employed as active homogenous catalysts for the epoxidation of alkenes [2,13-15]. However, these catalysts are toxic and expensive, and they must be completely separated from the products and waste. In this respect, the development of heterogeneous systems for improving the recovery of valuable cata- lysts is a very important aspect from an economic and ecological viewpoint. Furthermore, immobilization of the catalysts on supports with a high surface area in heterogeneous systems can efficiently improve the catalyst reactivity and enhance the turnover number (TON) of the catalytic procedure [2]. Anchoring catalysts on a solid surface disperses the active sites uniformly and protects them from dimerization by oxo-bridge formation [16]. Accordingly, various organic and inorganic materials have been used as insoluble supports in heterogeneous catalytic procedures. The organic insoluble supports include different types of polymers such as polybenzimidazole $[13,17]$, polystyrene $[13,18,19]$, polymethacrylate [13], polyaniline [20], and poly-divinylbenzene-allylamine [21]. In addition, ion exchange and epoxy resins [13,22], graphene oxide [23], multi-walled carbon nanotubes [16,24], ordered mesoporous carbon [25], silica [7,13,26], titanium silicate [13], MCM-41

* Corresponding author. Tel/Fax: +98-23-32395441; E-mail: mmirzaee@shahroodut.ac.ir 
[26-29], MCM-48 [29], SBA-15 [1,16,26,30,31], alumina [32], montmorillonite K-10 [13,33], coated magnetic particles $[13,34]$, zeolites [16,35-37] and layered bimetal hydroxides [5] have been used as insoluble supports. Generally, inorganic supports have a higher chemical stability and surface area than organic ones. Additionally, the surface of some metal oxides and metal hydroxides is covered with hydroxyl groups. These groups create hydrophilic surfaces that provide valuable sites for grafting a wide range of functionalities. Subsequently, supporting various transition metals on these functionalities can produce active and stable catalysts for liquid-phase organic reactions.

Boehmite $(\gamma-\mathrm{AlOOH})$ is an inorganic insoluble support that contains extra hydroxyl groups on its surface. It has been used as an absorbent, flame retardant [38], and an important precursor for preparing advanced catalysts, alumina, and alumina-derived ceramics [38,39]. We have used pure boehmite for the successful multi-component synthesis of highly substituted imidazoles [40]. Choudhary et al. [41] have also used pure boehmite for the catalytic epoxidation of styrene, although they reported that it was deactivated by the production and accumulation of water, and so it required continuous removal of water. Consequently, in this work, we used grafted boehmite nanoparticles (BNPs) with 3-(trimethoxysilyl)-propylamine (MSPA) to support two complexes of molybdenum and vanadium.

This strategy has been used for anchoring various metal complexes on different solid supports. However, almost all of them have changed the terminal amine group in MSPA to a Schiff base and then used it for the supporting metal complexes. We have also used this approach in our previous work [42]. In this work, grafted MSPA was used for the straight anchoring of metal complexes and then the supported catalysts were used in the epoxidation of various alkene substrates.

\section{Experimental}

\subsection{Materials and methods}

The required solvents and reagents were purchased from Merck or Fluka, and used without further purification. Fourier-transform infrared (FT-IR) spectra were recorded on a Bomem MB series FT-IR instrument at $4 \mathrm{~cm}^{-1}$ resolution using $\mathrm{KBr}$ pellets. ${ }^{1} \mathrm{H}$ NMR spectra were obtained in d6-DMSO using a Bruker AVANCE $300 \mathrm{MHz}$ spectrometer. Powder X-ray diffraction (PXRD) patterns were collected on a Phillips PW-1800 or STOE diffractometer with $\mathrm{Cu} K_{\alpha}$ irradiation. Thermogravimetric (TG) analyses were performed in a Rheometric Scientific STA- 1500 or BAHR Thermoanalyse $\mathrm{GmbH}$ with a heating rate of $10^{\circ} \mathrm{C} \mathrm{min}^{-1}$ in air. A 400-W Hg lamp was used for activation of the hexacarbonyl molybdenum complex. Elemental analyses were performed in a Hereans CHN-O-Rapid Analyzer. Transmission electron microscopy (TEM) was performed on a JEOL JSM-6360LV transmission electron microscope. Gas-liquid chromatography (GLC) was performed on a Shimadzu GC-16A instrument using a 2-m column packed with silicon DC-200. X-ray photoelectron spectroscopy (XPS) was performed on an
ESCA 2000 system from VG Microtech using a monochromatized aluminum $\mathrm{K} \alpha$ anode.

\subsection{Preparation of BNPS}

Aluminium 2-butoxide was prepared by the reaction of aluminium with 2-butanol according to the general preparation procedure for aluminium alkoxides [43]. The prepared aluminium alkoxide was vacuum-distilled to obtain a high-quality aluminium alkoxide precursor. For a hydrothermal-assisted hydrolysis, according to our previous report [44], aluminium 2-butoxide was diluted in 2-butanol to $50 \%$, and then loaded in a glass container. The glass container was placed in a $300-\mathrm{mL}$ stainless steel autoclave. The gap between the autoclave chamber and the glass container was covered with $50 \mathrm{~mL}$ of distilled water, and then the autoclave was heated at $100{ }^{\circ} \mathrm{C}$. Aluminium 2-butoxide was hydrolysed by diffusion of water vapour into the solution in the hydrothermal chamber. All manipulations of the aluminium alkoxides were performed on a Schlenk line. Their transfer into the autoclave was performed in a moisture-free atmosphere to prevent the hydrolysis of aluminium alkoxides prior to introducing it into the hydrothermal chamber. After $5 \mathrm{~h}$, the autoclave was cooled down and the powder produced (BNPs) was filtered off and dried at $100{ }^{\circ} \mathrm{C}$ overnight.

\subsection{Preparation of supported molybdenum and vanadium complexes on BNPs and amine-functionalized BNPS}

For the preparation of amine-functionalized BNPs (AFBNPs), $1.00 \mathrm{~g}$ of BNPs was refluxed with MSPA (61 $\mu \mathrm{L}, 0.35$ $\mathrm{mmol}$ ) in dry toluene $(50.0 \mathrm{~mL})$ for $24 \mathrm{~h}$ (Scheme 1). The solid substance obtained was filtered off, washed three times with dry toluene, and dried at $100^{\circ} \mathrm{C}$ overnight.

The Mo(CO) $)_{6}$ and $\mathrm{VOSO}_{4} \cdot \mathrm{H}_{2} \mathrm{O}$ complexes were used to support on BNPs or AFBNPs (Scheme 1). For this purpose, $\mathrm{Mo}(\mathrm{CO})_{6}(0.276 \mathrm{~g}, 1.05 \mathrm{mmol})$ was activated under ultraviolet light in tetrahydrofuran (THF, $20.0 \mathrm{~mL}$ ) for $30 \mathrm{~min}$. This activated molybdenum complex was then added to dry BNPs or AFBNPs, and the mixture was subsequently refluxed for $6 \mathrm{~h}$. The mixture was then cooled down and filtered off, and the resulting precipitate was washed several times with THF and dried at $100{ }^{\circ} \mathrm{C}$ overnight. In a similar procedure, $\mathrm{VOSO}_{4} \cdot \mathrm{H}_{2} \mathrm{O}$ $(0.200 \mathrm{~g}, 1.05 \mathrm{mmol})$ was refluxed with BNPs or AFBNPs in ethanol $(20 \mathrm{~mL})$ for $7 \mathrm{~h}$. The resulting powder was washed several times with ethanol and dried at $100^{\circ} \mathrm{C}$ overnight.

\subsection{Catalytic epoxidation of alkenes}

In a typical process, an appropriate round bottom flask equipped with a magnetic stirrer bar and a condenser was charged with an alkene, an oxidant, the catalyst (Mo-AFBNPs or V-AFBNPs), and solvent, and the mixture was then refluxed. All the reactions were performed at least two times, and the reaction progress was monitored by GLC. Because different alkenes have different reactivities toward oxidation, these reactions were continued until no further progress was observed. The 
characterizations of the main products and by-products were performed by comparison of their retention times with those for the standard samples. The alkene conversions and product selectivities were calculated using their peak areas by the standard addition method. In the case of cis- and trans-stilbene, ${ }^{1} \mathrm{H}$ NMR was also used to analyze the products.

\subsection{Catalyst recycling}

In a typical experiment, after recovering the catalyst from the reaction mixture, it was washed several times with $\mathrm{CCl}_{4}$, and then used in the same procedure under the same conditions.

\section{Results and discussion}

There are different methods that have been used for the preparation of BNPs. Among them, a hydrothermal-assisted sol-gel process on aluminum alkoxide was used here [44]. This method has some advantages such as preparation in a one-pot process and processing at a low temperature. The BNPs obtained were then grafted with MSPA because they showed no acceptable interaction with the molybdenum or vanadium complexes. The supported molybdenum and vanadium AFBNPs catalysts were then used in the epoxidation of cis-cyclooctene, and the experimental conditions were optimized for the parameters involved, such as the catalyst, solvent, and oxidant. Hot filtration was also used to confirm the heterogenic character of both catalytic procedures. In addition, recycling experiments were performed to determine if these catalysts could be reused. Both catalysts were then used for the epoxidation of different alkenes under the optimum experimental conditions.

\subsection{Preparation and characterization of supported molybdenum and vanadium complexes on BNPs and AFBNPS}

BNPs were prepared by the hydrothermal-assisted sol-gel processing of an aluminum 2-butoxide solution in 2-butanol.

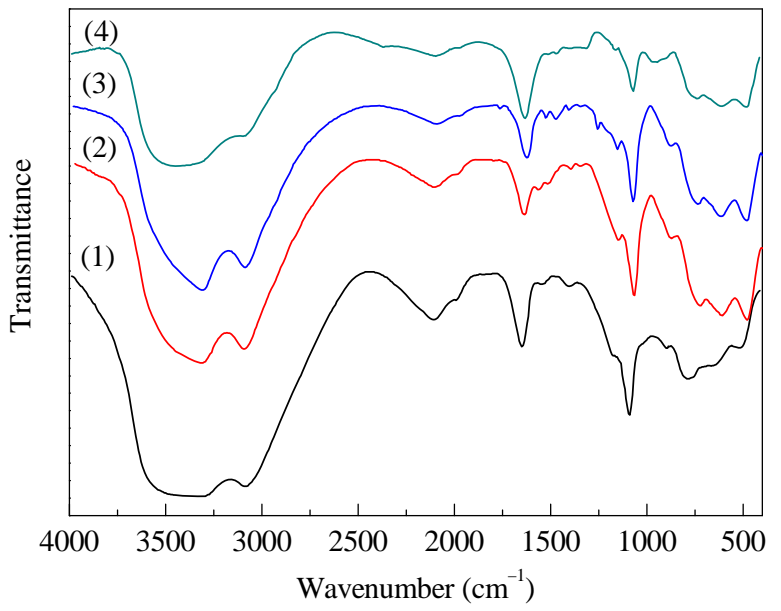

Fig. 1. FT-IR spectra for BNPs (1), AFBNPs (2), Mo-AFBNPs (3), and V-AFBNPs (4).

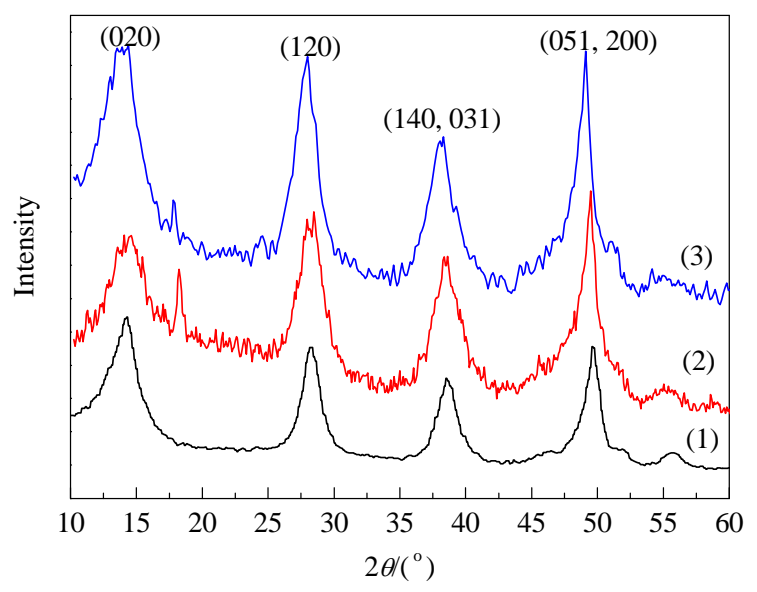

Fig. 2. PXRD patterns for BNPs (1), Mo-AFBNPs (2), and V-AFBNPs (3).

The most promising property of these hydrothermally processed BNPs is the formation of a crystalline single-phase product with no organic residue [44]. This was confirmed by the FT-IR spectrum, PXRD pattern, and TG/DSC thermogram of this sample.

In the FT-IR spectrum of BNPs (Fig. 1), there are two different stretching vibrations at 3280 and $3075 \mathrm{~cm}^{-1}$, which were assigned to the bridged and terminal hydroxyl groups of BNPs, respectively. These stretching vibrations were accompanied by two bending vibrations for the bridged and terminal hydroxyl groups at 1150 and $1075 \mathrm{~cm}^{-1}$, respectively. BNPs also had some distinguishable Al-0 related vibrations at 740,610, and $480 \mathrm{~cm}^{-1}$ in the IR spectrum. The PXRD pattern for BNPs (Fig. 2) also confirmed the crystallization of single-phase boehmite by comparison with JCPDS card No. 21-1307. In the TG/DSC curve of BNPs (Fig. 3(a)), there were two endothermic peaks:

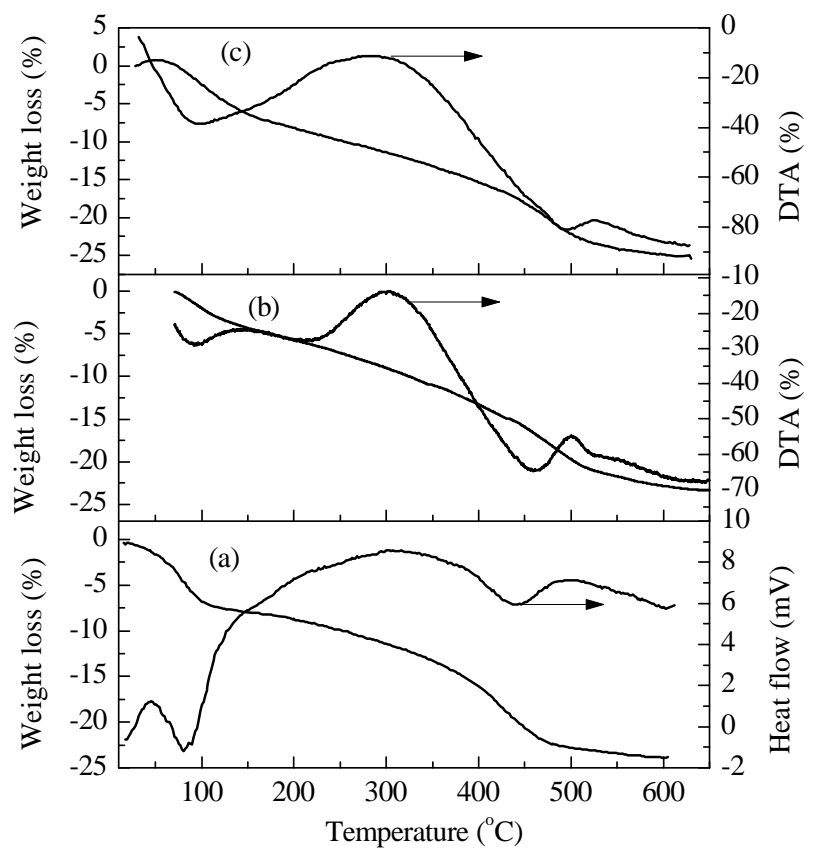

Fig. 3. Thermal analysis curves for BNPs (a), Mo-AFBNPs (b), and V-AFBNPs (c). 


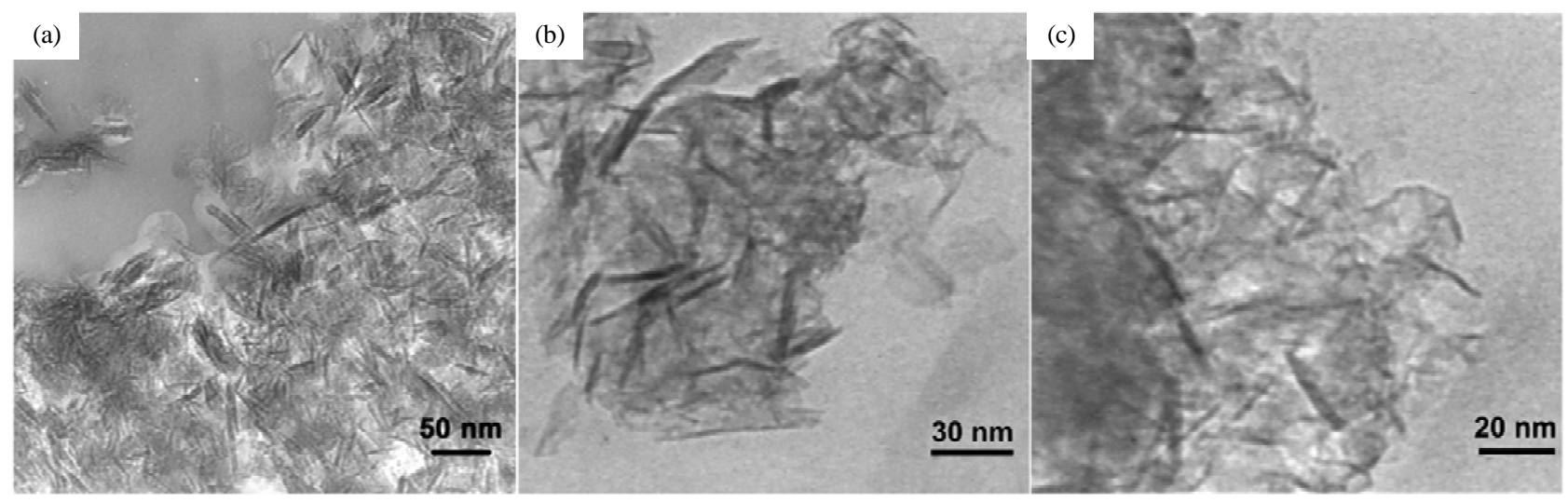

Fig. 4. TEM images for BNPs (a), Mo-AFBNPs (b), and V-AFBNPs (c).

one below $100{ }^{\circ} \mathrm{C}$ and the other one at approximately $450{ }^{\circ} \mathrm{C}$. The first one was attributed to the elimination of the physically adsorbed water, and the other one was attributed to the dehydroxylation of boehmite and crystallization of $\gamma$-alumina. The absence of the $\mathrm{C}-\mathrm{H}$ stretching vibrations in the IR spectrum and an exothermic peak at approximately $250{ }^{\circ} \mathrm{C}$ in the TG/DSC curve of BNPs, respectively, confirmed the loss of all organic residues in the hydrothermally processed BNPs. Calculation of the particle size using the PXRD pattern according to the Scherer equation shows an average particle size of $10 \mathrm{~nm}$ for BNPs. This was confirmed by TEM image of BNPs (Fig. 4(a)). In this image, needle-shaped BNPs were seen with a length of over $50 \mathrm{~nm}$ and a width of up to $10 \mathrm{~nm}$. According to the BET analysis, the efficient surface area for BNPs was $326 \mathrm{~m}^{2} \mathrm{~g}^{-1}$.

BNPs themselves have promising catalytic properties for multi-component synthesis of highly substituted imidazoles, as performed by our research team and reported elsewhere [40]. In addition, it has been shown that for an efficient epoxidation of alkenes under mild conditions, the presence of a catalyst containing an active metal site is vital. The oxidant could coordinate to this site, and be activated for the epoxidation process. However, BNPs showed no reactivity in the epoxidation of alkenes (Table 1, entry 30), similar to the report by Choudhary and co-workers [41]. Furthermore, supporting the molybdenum and vanadium complexes on BNPs failed (Scheme 1). The IR spectra and inductively coupled plasma (ICP) analyses showed no evidence to confirm an interaction between them even after 6-7 h reflux. Consequently, we tried to functionalize BNPs using MSPA. The functionalization was performed by refluxing BNPs and MSPA in dry toluene for $24 \mathrm{~h}$. During this process, the $-\mathrm{O}_{3} \mathrm{Si}\left(\mathrm{CH}_{2}\right)_{3} \mathrm{NH}_{2}$ group was grafted on the hydroxyl-covered surface of BNPs by the elimination of methanol (Scheme 1), which produced AFBNPs. The IR spectrum for AFBNPs (Fig. 1) showed a new band at $1553 \mathrm{~cm}^{-1}$, which was assigned to the $\mathrm{N}-\mathrm{H}$ stretching vibration of the grafted amine groups in addition to the BNPs characteristic bands. Elemental analysis showed that the nitrogen content of AFBNPs was $0.46 \%$, which means that $0.33 \mathrm{mmol}$ of the pending amine

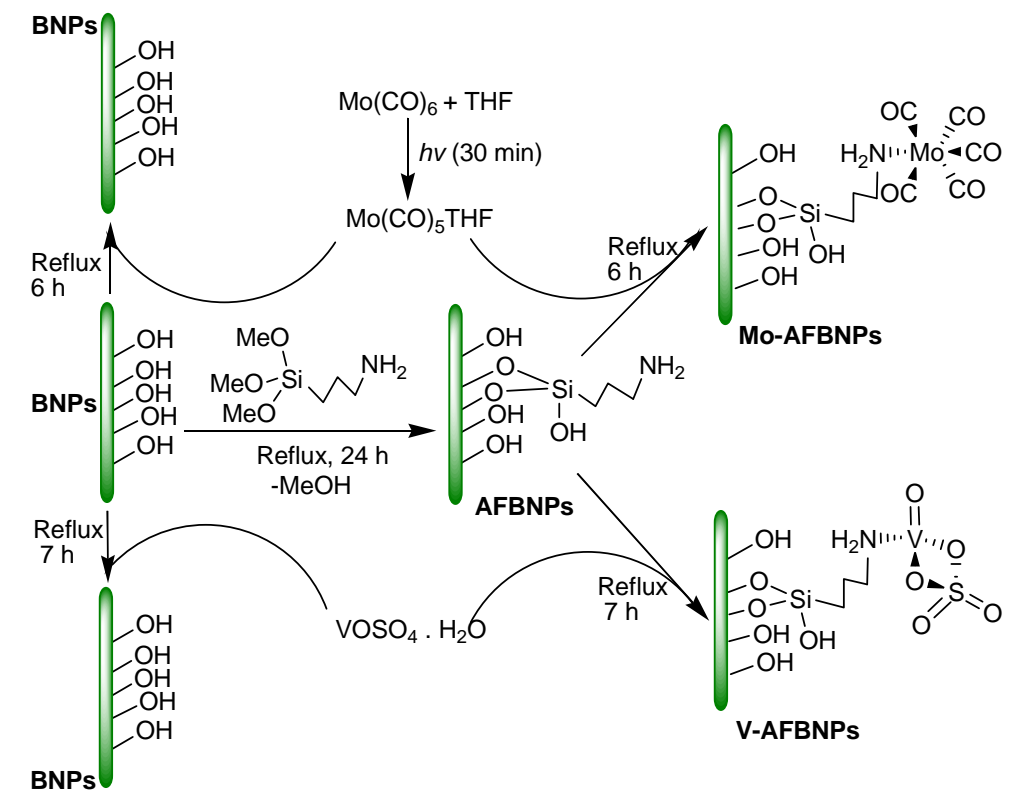

Scheme 1. Attempt to support molybdenum and vanadium complexes on BNPs and AFBNPs. 
groups were covalently bonded to the surface of $1.00 \mathrm{~g}$ of BNPs. AFBNPs also showed no reactivity in the catalytic epoxidation of alkenes (Table 1, entry 31), as it was predictable according to the above-mentioned discussion. The efficient BET surface area of AFBNPs was $321 \mathrm{~m}^{2} \mathrm{~g}^{-1}$, which does not show a significant change in comparison with BNPs.

AFBNPs were then used to support molybdenum and vanadium complexes. For this purpose, $\mathrm{Mo}(\mathrm{CO})_{6}$ and $\mathrm{VOSO}_{4} \cdot \mathrm{H}_{2} \mathrm{O}$ were used. However, $\mathrm{Mo}(\mathrm{CO})_{6}$ is not labile in the ligand substitution reaction, so its solution in THF was activated by irradiation with ultraviolet light. This process resulted in the formation of a Mo(CO) 5 (THF) complex, which substituted its THF ligand with the grafted amine group on BNPs after reflux for $6 \mathrm{~h}$ (Mo-AFBNPs). The $\mathrm{VOSO}_{4} \cdot \mathrm{H}_{2} \mathrm{O}$ complex was also refluxed with AFBNPs in ethanol for $7 \mathrm{~h}$ to support vanadium on AFBNPs (V-AFBNPs).

In the FT-IR spectrum of Mo-AFBNPs (Fig. 1), the carbonyl stretching vibration band for the coordinated molybdenum complex was covered by the characteristic broad band of the BNPs in the region of $1900-2500 \mathrm{~cm}^{-1}$. This was attributed to the small amount of catalyst that was loaded on AFBNPs. The ICP analysis showed that approximately $90 \%$ of the nitrogen sites on AFBNPs were used to anchor $0.3 \mathrm{mmol}$ of the molybdenum complex on $1.00 \mathrm{~g}$ of Mo-AFBNPs. The PXRD pattern of Mo-AFBNPs (Fig. 2) confirms the retention of the BNPs crystalline structure after functionalization and metal loading. There are two endothermic peaks in the TG/DTA curves for Mo-AFBNPs (Fig. 3(b)). One of them is below $100{ }^{\circ} \mathrm{C}$, and the other is above $200{ }^{\circ} \mathrm{C}$. The first was attributed to the elimination of physically adsorbed water, and the second could be attributed to the elimination of carbonyl ligands from the coordinated molybdenum complex. There is also an exothermic peak at approximately $300{ }^{\circ} \mathrm{C}$ owing to the ignition of the organic parts of the pending groups on the BNPs. This thermogram also shows another weight loss in the range of 400-500 ${ }^{\circ} \mathrm{C}$, which was accompanied with an endothermic peak in the DTA curve owing to the dehydroxylation of boehmite and crystallization of $\gamma$-alumina, similar to BNPs. The total weight loss of this sample up to $600{ }^{\circ} \mathrm{C}$ was about $24 \%$. Calculation of the particle size using the PXRD pattern for Mo-AFBNPs according to the Scherer equation shows no change in the particle size in comparison to BNPs, and this was confirmed by the TEM image (Fig. 4(b)). The efficient surface area for Mo-AFBNPs was 323 $\mathrm{m}^{2} \mathrm{~g}^{-1}$, which does not show a significant variation in comparison with BNPs and AFBNPs.

The IR spectrum of V-AFBNPs (Fig. 1) shows a new band at $956 \mathrm{~cm}^{-1}$ owing to the $\mathrm{V}=0$ stretching vibration of the $\mathrm{VOSO}_{4}$ complex, which confirms the coordination of the vanadium complex to the functionalized BNPs. The ICP analysis also showed that over $80 \%$ of the nitrogen sites on AFBNPs were used to anchor $0.28 \mathrm{mmol}$ of the vanadium complex on $1.00 \mathrm{~g}$ of V-AFBNPs, which is lower than the metal loading in Mo-AFBNPs. The PXRD pattern of V-AFBNPs (Fig. 2) also confirms retention of the crystalline structure of the BNPs after metal loading. In the TG/DTA curve of V-AFBNPs (Fig. 3(c)), there is an endothermic peak below $100{ }^{\circ} \mathrm{C}$ with $6 \%$ weight loss in the TG curve owing to the elimination of the physically adsorbed water. Similar to the molybdenum counterpart, there is an exothermic peak at approximately $300{ }^{\circ} \mathrm{C}$ owing to the ignition of the organic parts of AFBNPs. Additionally, and similar to BNPs and Mo-AFBNPs, this thermogram shows a weight loss in the range of $400-500{ }^{\circ} \mathrm{C}$, accompanied by an endothermic peak in the DTA curve, which was similarly assigned as resulting from dehydroxylation of boehmite and crystallization of $\gamma$-alumina. The total weight loss of V-AFBNPs up to $600{ }^{\circ} \mathrm{C}$ was about $24 \%$, similar to Mo-AFBNPs. Calculation of the particle size using the PXRD pattern for V-AFBNPs according to the Scherer equation, and similar to the molybdenum counterpart, shows no change in the particle size in comparison to BNPs. This was also confirmed by the TEM image (Fig. 4(c)).

The efficient surface area for V-AFBNPs was $318 \mathrm{~m}^{2} \mathrm{~g}^{-1}$, which does not show a significant variation in comparison with BNPs, AFBNPs, and Mo-AFBNPs. The XPS analysis was also performed for further evidence of the surface compositions of both the Mo-AFBNPs and V-AFBNPs catalysts inferred by the FT-IR and ICP analyses. Wide scan XPS spectra of both catalysts over a wide binding energy range from 0 to $600 \mathrm{eV}$ are displayed in Fig. 5. In the case of Mo-AFBNPs catalyst (Fig. 5), the XPS Mo $3 d_{5 / 2}$ and Mo $3 d_{3 / 2}$ peaks were observed at 232 and $236 \mathrm{eV}$, respectively, indicating the presence of a molybdenum complex on the surface of this catalyst. However, in the case of the V-AFBNPs catalyst (Fig. 5), the XPS V $2 p_{3 / 2}$ and V $2 p_{1 / 2}$

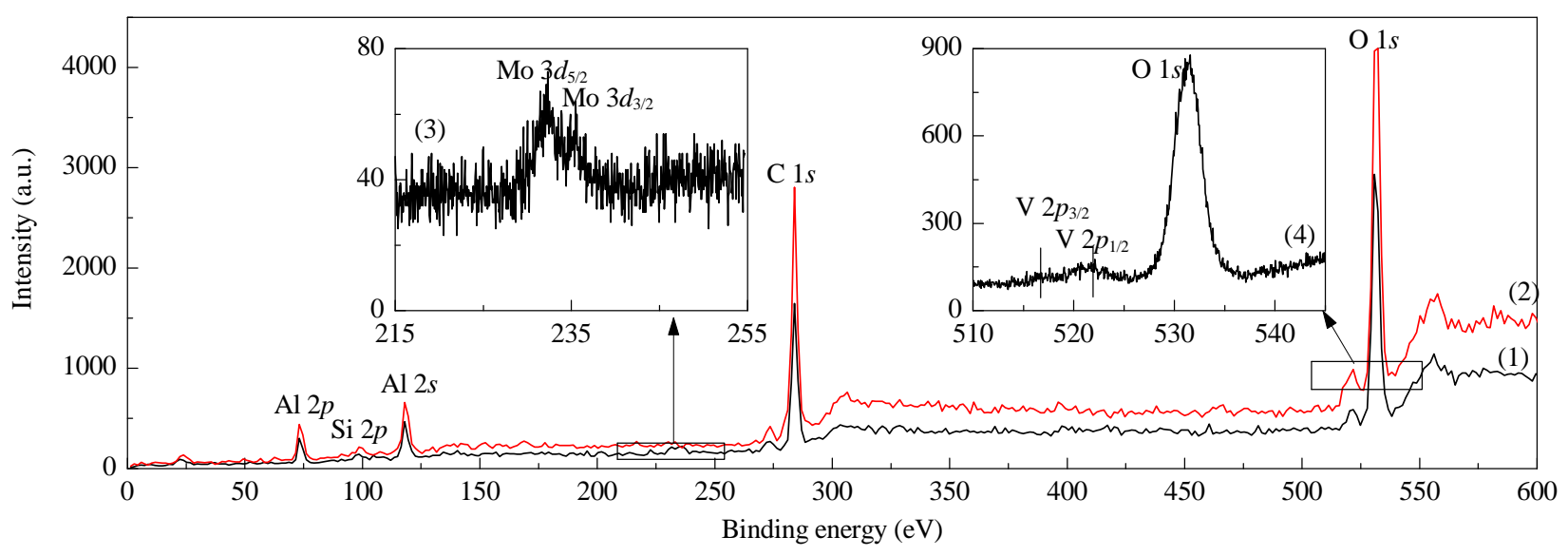

Fig. 5. XPS analysis of Mo-AFBNPs (1), V-AFBNPs (2), Mo $3 d$ region (3) of Mo-AFBNPs, and V $2 p$ and 0 1s region (4) of V-AFBNPs. 
peaks at 517 and $522 \mathrm{eV}$, respectively, indicates the presence of a vanadium complex on the surface of this catalyst. The XPS Si $2 p$ and $\mathrm{C} 1 s$ peaks at 99 and $284 \mathrm{eV}$, respectively, confirmed the attachment of the silylpropyl amine group on the surface of boehmite nanoparticles in both catalysts. In addition, the XPS $\mathrm{Al} 2 p, \mathrm{Al} 2 s$, and $\mathrm{O} 1 s$ peaks at 72, 117, and $530 \mathrm{eV}$, respectively, owing to the BNPs, were present in the spectra of both catalysts. In brief, the surface compositions characterized by the FT-IR, ICP, and XPS analyses support each other.

\section{2. $\quad$ Alkene epoxidation with tert-butylhydroperoxide catalyzed by Mo-AFBNPs and V-AFBNPS}

Epoxidation of cyclooctene has been widely used as a model reaction to demonstrate the catalytic activities of new synthesized catalysts. This reaction was chosen because cyclooctene epoxide is the only product and it does not have any other byproduct. Thus, we used this reaction to show and optimize the catalytic activities of our catalysts. The optimization of the title reaction was investigated by changing different parameters including the solvent, oxidant, catalyst, and time. Our experiments showed that in the presence of these catalysts, tert-butylhydroperoxide (TBHP) was the only oxidizing system that can promote the epoxidation of cis-cyclooctene in $\mathrm{CCl}_{4}$
Other oxygen sources such as hydrogen peroxide and sodium periodate (in the presence of $0.01 \mathrm{~g}$ of tetrabutylphosphonium bromide as the phase-transfer reagent), and urea-hydrogen peroxide in $\mathrm{CCl}_{4}$ or $\mathrm{CH}_{3} \mathrm{CN}$ do not show an acceptable activity. It seems that the protic solvents, which were inevitably present with those oxidants, competed to bind to the metal complexes, and blocked the catalytic sites. Furthermore, under mild conditions, the epoxidation of cis-cyclooctene by TBHP did not proceed in the absence of the catalyst.

As shown in Table 1 (entries 1-6 and 17-22), the use of different solvents showed the same trend as other literature reports on homogeneous alkene epoxidation by the $\mathrm{Mo}(\mathrm{CO})_{6}$ catalyst [45]. Coordinating solvents such as $\mathrm{CH}_{3} \mathrm{CN}$ and $\mathrm{CH}_{3} \mathrm{OH}$ compete with TBHP to occupy the coordination sites on the transition metal catalyst. Therefore, in the presence of these solvents, the observed yields are very low. Among other solvents, $\mathrm{CCl}_{4}$ has the highest yield of epoxide product for both the Mo-AFBNPs and V-AFBNPs catalysts. This could be attributed to the higher boiling point of $\mathrm{CCl}_{4}$ in comparison to the other solvents.

We then determined how the amount of the amine group anchored on BNPs influenced the progress of the reaction (Table 1, entries 6-8). For this purpose, different amounts of MSPA (6:0.35, 7:0.7, and 8:0.23 mmol) were used to anchor $1.00 \mathrm{~g}$ of

Table 1

Epoxidation of cis-cylooctene with TBHP under reflux conditions after $2 \mathrm{~h}$.

\begin{tabular}{|c|c|c|c|c|c|c|}
\hline Entry & Catalyst (mg) & Solvent (mL) & $\begin{array}{l}\text { Pending amine group } \\
\text { (mmol)/BNPs (g) }\end{array}$ & $\begin{array}{c}\text { Catalyst loading a } \\
\text { (mol \%) }\end{array}$ & $\begin{array}{c}\text { Oxidant/Substrate } \\
\text { molar ratio }\end{array}$ & $\begin{array}{c}\text { Epoxide yield }{ }^{\mathrm{b}} \\
(\%)\end{array}$ \\
\hline 1 & Mo-AFBNPs (40) & $\mathrm{CH}_{3} \mathrm{CN}(3)$ & 0.35 & 1.7 & 1.5 & No reaction \\
\hline 2 & Mo-AFBNPs (40) & $\mathrm{CH}_{3} \mathrm{OH}(3)$ & 0.35 & 1.7 & 1.5 & No reaction \\
\hline 3 & Mo-AFBNPs (40) & $\left(\mathrm{CH}_{3}\right)_{2} \mathrm{CO}(3)$ & 0.35 & 1.7 & 1.5 & 18 \\
\hline 4 & Mo-AFBNPs (40) & $\mathrm{CH}_{2} \mathrm{Cl}_{2}(3)$ & 0.35 & 1.7 & 1.5 & 23 \\
\hline 5 & Mo-AFBNPs (40) & $\mathrm{CHCl}_{3}(3)$ & 0.35 & 1.7 & 1.5 & 40 \\
\hline 6 & Mo-AFBNPs (40) & $\mathrm{CCl}_{4}(3)$ & 0.35 & 1.7 & 1.5 & 53 \\
\hline 7 & Mo-AFBNPs (40) & $\mathrm{CCl}_{4}(3)$ & 0.70 & 2.0 & 1.5 & 55 \\
\hline 8 & Mo-AFBNPs (40) & $\mathrm{CCl}_{4}(3)$ & 0.23 & 0.8 & 1.5 & 40 \\
\hline 9 & Mo-AFBNPs (30) & $\mathrm{CCl}_{4}(3)$ & 0.35 & 1.29 & 1.5 & 53 \\
\hline 10 & Mo-AFBNPs (20) & $\mathrm{CCl}_{4}(3)$ & 0.35 & 0.86 & 1.5 & 63 \\
\hline 11 & Mo-AFBNPs (10) & $\mathrm{CCl}_{4}(3)$ & 0.35 & 0.43 & 1.5 & 46 \\
\hline 12 & Mo-AFBNPs (20) & $\mathrm{CCl}_{4}(3)$ & 0.35 & 0.86 & 1 & 42 \\
\hline 13 & Mo-AFBNPs (20) & $\mathrm{CCl}_{4}(3)$ & 0.35 & 0.86 & 2 & 79 \\
\hline 14 & Mo-AFBNPs (20) & $\mathrm{CCl}_{4}(3)$ & 0.35 & 0.86 & 2.5 & 83 \\
\hline 15 & Mo-AFBNPs (20) & $\mathrm{CCl}_{4}(2)$ & 0.35 & 0.86 & 2 & 86 \\
\hline 16 & Mo-AFBNPs (20) & $\mathrm{CCl}_{4}(1)$ & 0.35 & 0.86 & 2 & 96 \\
\hline 17 & V-AFBNPs (20) & $\mathrm{CH}_{3} \mathrm{CN}(3)$ & 0.35 & 0.8 & 2 & 8 \\
\hline 18 & V-AFBNPs (20) & $\mathrm{CH}_{3} \mathrm{OH}(3)$ & 0.35 & 0.8 & 2 & 10 \\
\hline 19 & V-AFBNPs (20) & $\left(\mathrm{CH}_{3}\right)_{2} \mathrm{CO}(3)$ & 0.35 & 0.8 & 2 & 35 \\
\hline 20 & V-AFBNPs (20) & $\mathrm{CH}_{2} \mathrm{Cl}_{2}(3)$ & 0.35 & 0.8 & 2 & 61 \\
\hline 21 & V-AFBNPs (20) & $\mathrm{CHCl}_{3}(3)$ & 0.35 & 0.8 & 2 & 68 \\
\hline 22 & V-AFBNPs (20) & $\mathrm{CCl}_{4}(3)$ & 0.35 & 0.8 & 2 & 73 \\
\hline 23 & V-AFBNPs (10) & $\mathrm{CCl}_{4}(3)$ & 0.35 & 0.4 & 2 & 57 \\
\hline 24 & V-AFBNPs (30) & $\mathrm{CCl}_{4}(3)$ & 0.35 & 1.2 & 2 & 67 \\
\hline 25 & V-AFBNPs (40) & $\mathrm{CCl}_{4}(3)$ & 0.35 & 1.6 & 2 & 63 \\
\hline 26 & V-AFBNPs (20) & $\mathrm{CCl}_{4}(3)$ & 0.35 & 0.8 & 1 & 53 \\
\hline 27 & V-AFBNPs (20) & $\mathrm{CCl}_{4}(3)$ & 0.35 & 0.8 & 3 & 76 \\
\hline 28 & V-AFBNPs (20) & $\mathrm{CCl}_{4}(2)$ & 0.35 & 0.8 & 2 & 80 \\
\hline 29 & V-AFBNPs (20) & $\mathrm{CCl}_{4}(1)$ & 0.35 & 0.8 & 2 & 83 \\
\hline 30 & BNPs (20) & $\mathrm{CCl}_{4}(3)$ & 0.35 & - & 2 & No reaction \\
\hline 31 & AFBNPs (20) & $\mathrm{CCl}_{4}(3)$ & 0.35 & - & 2 & No reaction \\
\hline
\end{tabular}

${ }^{a}$ Calculated for $0.7 \mathrm{mmol}$ cyclooctene. ${ }^{\mathrm{b}} \mathrm{GLC}$ yields are based on the starting cyclooctene. 
BNPs. These functionalized BNPs were then used to support $\mathrm{Mo}(\mathrm{CO})_{6}$. These catalysts were then used for the epoxidation of $0.7 \mathrm{mmol}$ of cis-cyclooctene with $1.05 \mathrm{mmol}$ of TBHP. The results obtained showed that after $2 \mathrm{~h}$ the conversions of entries 6 and 7 were the same and higher than entry 8, respectively. Therefore, $0.35 \mathrm{mmol}$ of the pending amine group per gram of BNPs was selected for further investigations. According to the ICP analysis, the amount of supported molybdenum complexes on samples 6,7 , and 8 were $0.3,0.35$, and $0.14 \mathrm{mmol} \mathrm{g}^{-1}$, respectively. The same activities for entries 6 and 7 may be attributed to almost the same metal loading on AFBNPs.

The amount of catalyst used for the epoxidation of cis-cyclooctene with TBHP was also investigated. Fig. 6 and Table 1 (entries 6, 9-11, and 22-25) confirm that increasing the amount of both the Mo-AFBNPs and V-AFBNPs catalysts up to $20 \mathrm{mg}$ increased the cyclooctene epoxide yield.

The oxidant to substrate ratio is one of the most crucial parameters in the catalytic epoxidation processes. The results tabulated in Table 1 (entries 10, 12-14, 22, 26, and 27) show that the optimum oxidant to substrate ratio for both catalysts was 2. Increasing this ratio to 2.5 and 3 for Mo-AFBNPs and V-AFBNPs, respectively, did not change the epoxidation yields significantly, but decreasing the ratio to 1 lowered the yields significantly.

The amount of solvent was also investigated. The results (Table 1, entries 13, 15, 16, 22, 28, and 29) show that decreasing the amount of solvent from 3 to $1 \mathrm{~mL}$ increases the epoxide yield.

Fig. 7 shows the effect of reaction time on the epoxidation of cis-cyclooctene with TBHP. A comparison between the reactivities of the Mo-AFBNPs and V-AFBNPs catalysts reveals that the supported molybdenum catalyst is more reactive, and after 90 min, its conversion reaches a maximum, and then becomes constant. However, the supported vanadium complex requires $180 \mathrm{~min}$ to reach this goal.

Moreover, the heterogenic character of these catalysts was checked by a hot filtration test. For this purpose, each catalyst was removed by centrifuging the catalytic reaction mixture at the halfway point of the optimum reaction time, which had

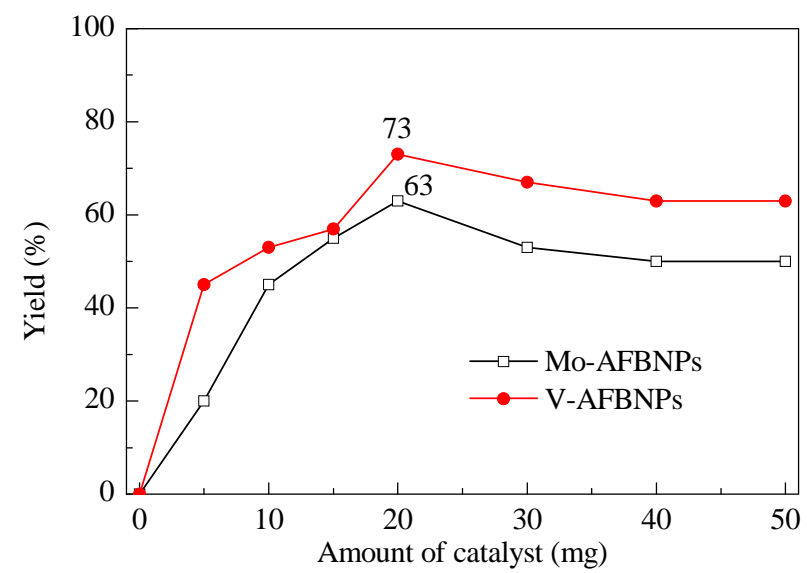

Fig. 6. Epoxidation of $0.7 \mathrm{mmol}$ of cis-cyclooctene with $1.4 \mathrm{mmol}$ of

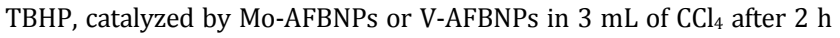
under reflux conditions.

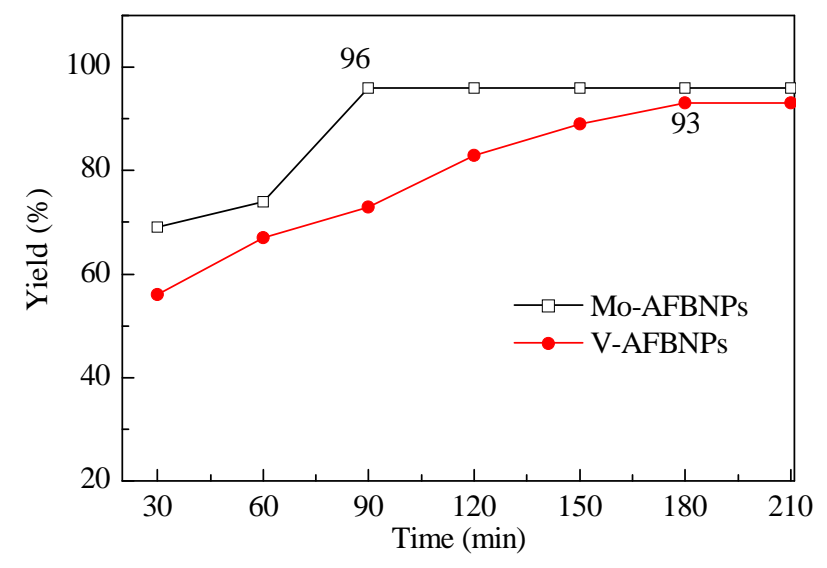

Fig. 7. Epoxidation of $0.7 \mathrm{mmol}$ of cis-cyclooctene with $1.4 \mathrm{mmol}$ of

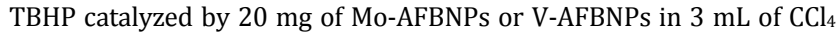
under reflux conditions.

been determined earlier. The reaction was then allowed to continue and reach the optimum reaction time without the presence of the catalyst. The results obtained showed that when the catalyst was removed from the reaction medium, the catalytic procedure stopped and did not continue anymore. This test proves that the catalytic reactions proceeded in heterogeneous conditions and the catalysts were not leached into the reaction medium.

We also studied the reaction progress in the presence of the related homogenous catalysts. The results showed that by using $\mathrm{Mo}(\mathrm{CO})_{6}$ or $\mathrm{VOSO}_{4} \cdot \mathrm{H}_{2} \mathrm{O}$ as the catalyst under the same experimental conditions for the heterogeneous counterparts, the reaction yields reduced to $85 \%$ and $55 \%$, respectively. The greater reactivities of the heterogeneous Mo-AFBNPs and V-AFBNPs catalysts may be related to the homogenous dispersion of the catalytic active sites onto the surface of BNPs, which efficiently increased the effective collision of the reagents to the metal sites, and consequently, increased the cyclooctene epoxide yield in comparison to the homogeneous counterparts. In addition, anchoring the molybdenum and vanadium complexes onto the BNPs surface protect them from dimerization by oxo-bridge formation, which leads to the deactivation of the catalytic sites and lowers the yields in homogenous reaction conditions.

The new catalysts Mo-AFBNPs and V-AFBNPs can also be used for the epoxidation of a wide range of substituted alkenes (Table 2). The blank experiments, performed without catalysts, with BNPs or AFBNPs, showed a very low conversion even after $5 \mathrm{~h}$ reflux. In the presence of Mo-AFBNPs and V-AFBNPs, a wide range of both the cyclic and linear alkenes could efficiently and selectively be converted to epoxides. Based on the epoxidation mechanisms suggested earlier [44], the higher electron-donating ability of an alkene double bond is expected to show more epoxidation reactivity. Therefore, cyclooctene and cyclohexene with inner double bonds should exhibit more activity in comparison with 1-hexene and 1-octene, which contain terminal double bonds. In addition, cyclooctene is more reactive than cyclohexene owing to some cyclooctene confor- 
Table 2

Epoxidation of some alkenes with TBHP catalyzed by Mo-AFBNPs or V-AFBNPs under reflux conditions.

\begin{tabular}{|c|c|c|c|c|c|c|c|}
\hline \multirow[b]{2}{*}{ Entry } & \multirow[b]{2}{*}{ Alkene } & \multicolumn{3}{|c|}{ Mo-AFBNPs a } & \multicolumn{3}{|c|}{ V-AFBNP } \\
\hline & & Conversion ${ }^{\mathrm{b}}(\%)$ & $\begin{array}{c}\text { Epoxide }{ }^{b} \\
\left.\text { (\%) (large scale }{ }^{c}\right)\end{array}$ & $\begin{array}{l}\text { Time } \\
(\mathrm{h})\end{array}$ & Conversion ${ }^{\mathrm{b}}(\%)$ & $\begin{array}{c}\text { Epoxide }^{b} \\
(\%)\left(\text { large scale }^{c}\right)\end{array}$ & Time (h) \\
\hline 1 & & 96 & $96(92)$ & 1.5 & 93 & $93(88)$ & 3 \\
\hline 2 & & $98^{d}$ & $70(67)$ & 1.5 & $92^{\mathrm{d}}$ & $85(81)$ & 3 \\
\hline 3 & & 60 & $60(55)$ & 6 & 58 & $58(54)$ & 10 \\
\hline 4 & & 68 & $68(63)$ & 6 & 60 & $60(55)$ & 10 \\
\hline 5 & & $88^{e}$ & $81(77)$ & 6 & 87 e & $66(61)$ & 10 \\
\hline 6 & & $98^{f}$ & $86(81)$ & 1.5 & $89^{f}$ & $80(76)$ & 3 \\
\hline 7 & & $99 \mathrm{~g}$ & 99 trans $^{\mathrm{h}}$ & 3 & $98 \mathrm{~g}$ & 98 trans $^{\mathrm{h}}$ & 6 \\
\hline 8 & & $92 \mathrm{~g}$ & 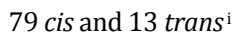 & 3 & $90 \mathrm{~g}$ & 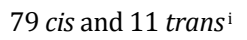 & 6 \\
\hline
\end{tabular}

a GLC yield based on the starting alkenes.

b Reaction conditions: alkene $0.7 \mathrm{mmol}$, TBHP $1.4 \mathrm{mmol}$, catalyst $20 \mathrm{mg}, \mathrm{CCl}_{4} 1 \mathrm{~mL}$.

c Large scale reaction conditions: alkene $14 \mathrm{mmol}$, TBHP $28 \mathrm{mmol}$, catalyst $0.4 \mathrm{~g}, \mathrm{CCl}_{4} 20 \mathrm{~mL}$.

d The byproduct (cyclohexanone) is $18 \%$ for Mo-AFBNPs and $7 \%$ for V-AFBNPs.

e The byproduct (benzaldehyde) is 7\% for Mo-AFBNPs and 21\% for V-AFBNPs.

f The byproduct (acetophenone ) is $12 \%$ for Mo-AFBNPs and $9 \%$ for V-AFBNPs.

gBoth ${ }^{1} \mathrm{H}$ NMR and GLC data approved the reported yields.

h Trans isomer is the only product, according to ${ }^{1} \mathrm{H}$ NMR data.

${ }^{\mathrm{i}}$ Cis and trans isomers are both produced, according to ${ }^{1} \mathrm{H}$ NMR data.

mations that favor the formation of reaction intermediates that decrease the activation energy [46]. In contrast, 1-octene is oxidized slower than 1-hexene, and this observation could be attributed to the more steric hindrance of the hexyl group connected to the double bond present in 1-octene in comparison with the butyl group in 1-hexene. A larger hexyl group can effectively hinder the approach of 1-octene to the catalyst metal center, and slow down the reaction. Cis- and trans-stilbene were also completely converted to epoxides by the Mo-AFBNPs and V-AFBNPs catalysts. Surprisingly, trans-stilbene gives only a trans epoxide, and cis-stilbene gives a mixture with a high cis/trans epoxide molar ratio (Table 2). This shows the high selectivities of these catalysts in the epoxidation of alkenes. In addition, we scaled-up the reaction and reported the results obtained in Table 2 . These results show only a $4 \%-6 \%$ reduction in the epoxide yields of different alkenes in comparison to the small-scale experiment, and they confirmed the potential use of these catalytic protocols in industrial procedures.

Based on the Sobczak's report [47] and other experimental and theoretical reports $[2,7,15,45]$, probable mechanisms were proposed for the epoxidation of cyclooctene with TBHP by the Mo-AFBNPs and V-AFBNPs catalysts (Schemes 2 and 3). According to our experimental results, the reaction rates display a first-order dependence on the catalyst and substrate concentrations. There are also some crucial stages in these processes. The V-AFBNPs catalyst initially contains the oxo ligand on its metal center but, for Mo-AFNBPs, the pending molybdenum complex is oxidized in the first step, and an oxo-molybdenum complex is formed. The next step for both catalysts involves the transfer of the TBHP hydroxyl proton to a terminal oxygen atom of these охо complexes, which results in the coordination of the tert-butylperoxide anion to the Lewis acidic metal centers. Then the alkene substrate is coordinated to the metal center, and, as a nucleophile, is inserted into the metal oxygen bond of the coordinated peroxide electrophile anion. This mechanism easily explains the faster reaction of the electron-rich alkenes in comparison to the electron-poor ones. In the next step, the epoxide product is formed, and the tert-butylperoxide anion is converted to the tert-butoxide anion. Then the peroxide product is released and the catalytic cycle is continued by substitution of a new tert-butylperoxide instead of the tert-butoxide anion.

\subsection{Catalyst recovery and reuse}

As discussed earlier, the reusability of solid-supported cata- 


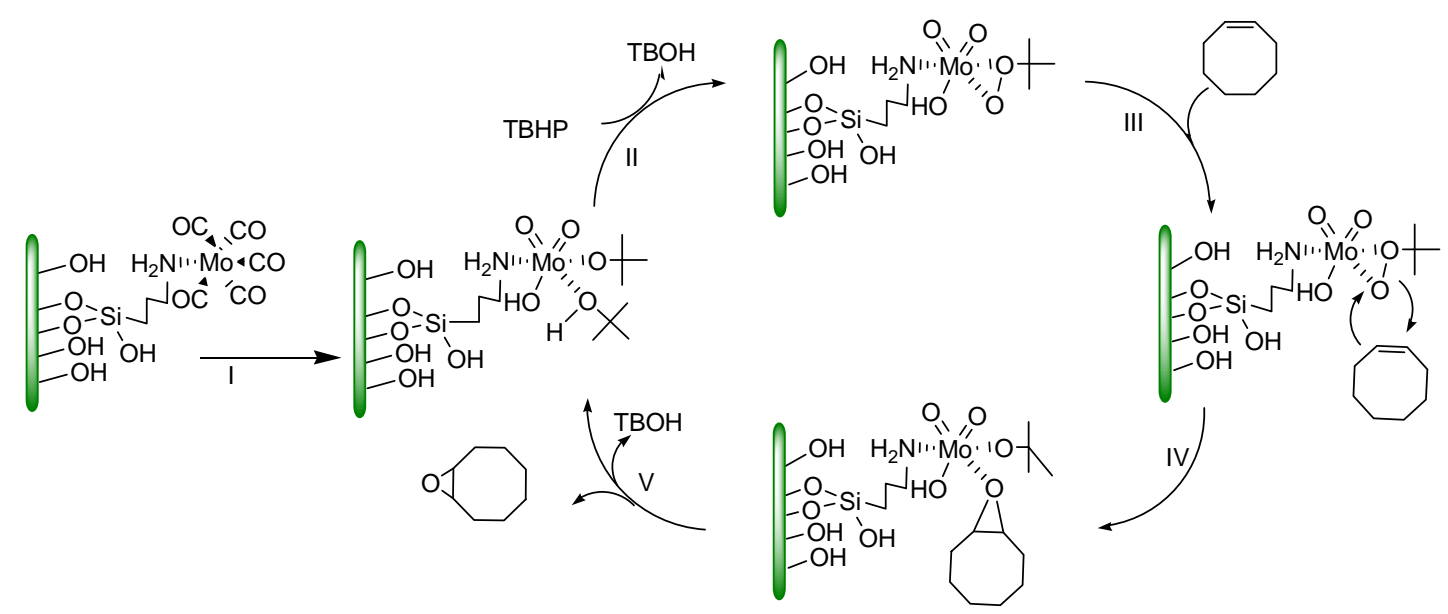

Scheme 2. Proposed mechanism for epoxidation of alkenes with TBHP by Mo-AFBNPs.
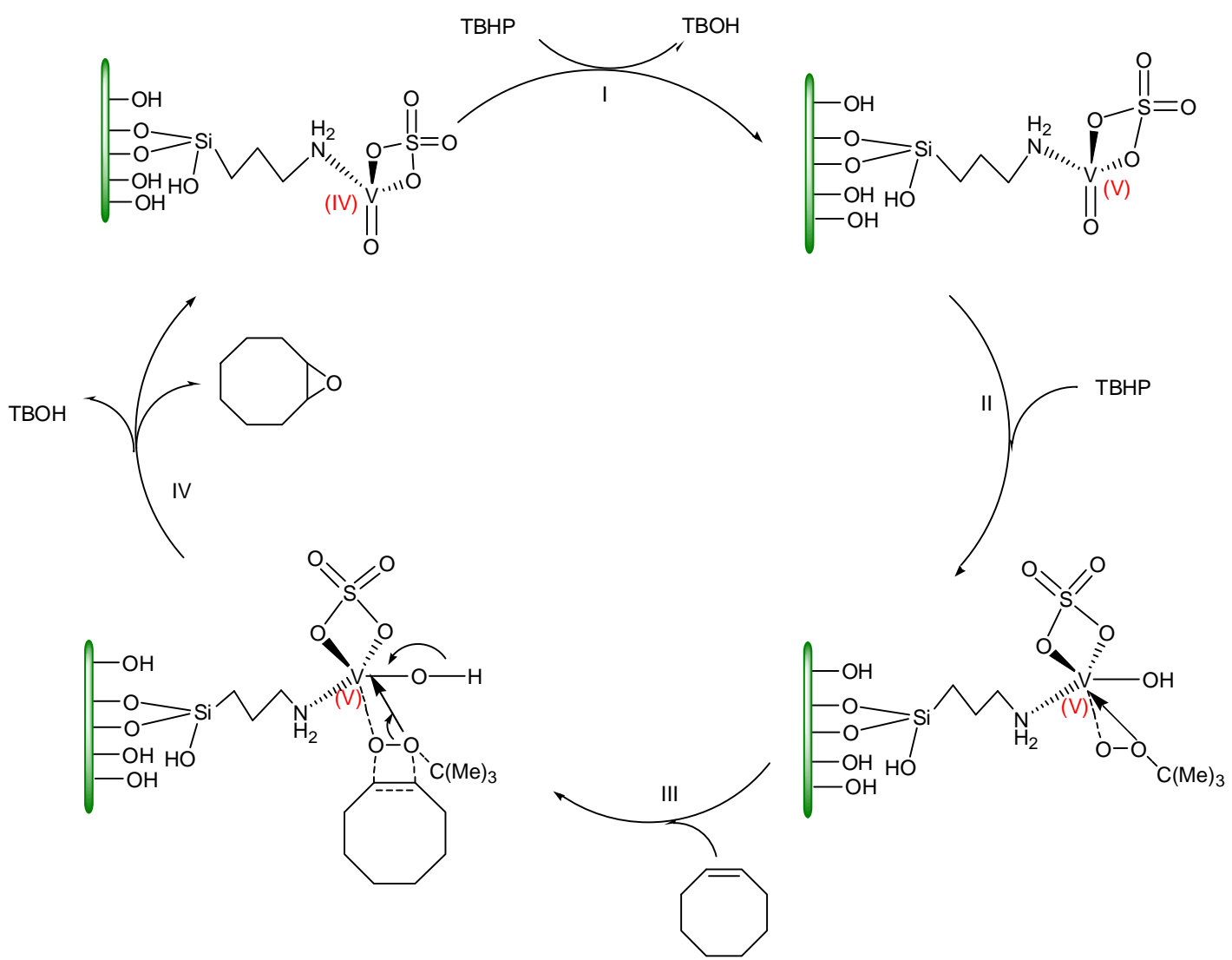

Scheme 3. Proposed mechanism for epoxidation of alkenes with TBHP by V-AFBNPs.

lysts is one of their most important benefits. Therefore, the reusability of the Mo-AFBNPs and V-AFBNPs catalysts was monitored by means of multiple sequential epoxidations of cis-cyclooctene with TBHP (Table 3). After each cycle, the reaction mixture was centrifuged, and the supernatant solutions and recovered catalysts were analyzed by ICP. This analysis showed that there was no metal contaminant in the supernatant solution, and no decrease in the metal loading of the recovered catalyst. It also confirmed that the metal ions did not leach from the heterogeneous catalysts, and that the reactions were performed entirely under heterogeneous conditions. In addition, retention of the catalytic activity, up to five cycles, for recovered Mo-AFBNPs, makes it a better candidate for the epoxidation of alkenes. The reason for the small gradual decrease in the yields with V-AFBNPs was attributed to the poisoning effect of water vapor, which may be adsorbed during the recovering process and blocks the catalytic sites on the metal center.

Turnover frequency (TOF) is a virtuous parameter for the comparison of the catalytic activities, so we used it to show the 
Table 3

Epoxidation of cis-cylooctene with TBHP under reflux conditions using recycled catalysts.

\begin{tabular}{|c|c|c|c|c|c|c|c|c|}
\hline \multirow{2}{*}{$\begin{array}{l}\text { Number of } \\
\text { cycles }\end{array}$} & \multicolumn{4}{|c|}{ Mo-AFBNPs catalyst a } & \multicolumn{4}{|c|}{ V-AFBNPs catalyst ${ }^{b}$} \\
\hline & Epoxide yield c (\%) & TOF d $\left(\mathrm{h}^{-1}\right)$ & Leached e (\%) & $\begin{array}{l}\text { Content }^{\mathrm{f}} \\
(\mathrm{mmol} / \mathrm{g})\end{array}$ & $\begin{array}{c}\text { Epoxide yield c } \\
(\%)\end{array}$ & $\begin{array}{l}\text { TOF d } \\
\left(\mathrm{h}^{-1}\right)\end{array}$ & Leached e (\%) & $\begin{array}{r}\text { Content }{ }^{\mathrm{f}} \\
(\mathrm{mmol} / \mathrm{g})\end{array}$ \\
\hline 1 & 96 & 75 & ND & 0.3 & 93 & 39 & ND & 0.28 \\
\hline 2 & 92 & 72 & ND & 0.29 & 91 & 38 & ND & 0.28 \\
\hline 3 & 90 & 70 & ND & 0.29 & 90 & 37 & ND & 0.27 \\
\hline 4 & 90 & 70 & ND & 0.3 & 87 & 36 & ND & 0.27 \\
\hline$\underline{5}$ & 90 & 70 & ND & 0.29 & 85 & 35 & ND & 0.28 \\
\hline
\end{tabular}

a Reaction conditions: cyclooctene $0.7 \mathrm{mmol}$, TBHP $1.4 \mathrm{mmol}$, catalyst $20 \mathrm{mg}, \mathrm{CCl}_{4} 1 \mathrm{~mL}, 90 \mathrm{~min}$.

b Reaction conditions: cyclooctene $0.7 \mathrm{mmol}$, TBHP $1.4 \mathrm{mmol}$, catalyst $20 \mathrm{mg}, \mathrm{CCl}_{4} 1 \mathrm{~mL}, 180 \mathrm{~min}$.

c GLC yields are based on the starting cyclooctene.

$\mathrm{d}$ TOF $=$ mole of reactant $\times$ yield $/(100 \times$ mole of catalyst $\times$ time $)$

e Metal leached from catalyst into the catalytic solution medium determined by ICP.

f Metal content of recycled catalyst determined by ICP.

ND-Not detected

benefits of our catalytic systems over other reported catalytic protocols. Very recently, Feng et al. [21] have supported a dioxo-molybdenum complex onto an organic copolymer and reached a TOF of 5 in the epoxidation of cis-cyclooctene with TBHP. Sakthivel et al. [31] have supported Mo(CO)6 on SBA-15 and reported a TOF of 32 in the same reaction. Moahmmadikish et al. [48] have supported a molybdenum complex onto nanomagnetite and reported a TOF of 19 with the same catalytic reaction conditions. Yang et al. [49] have also supported a molybdenum Schiff base complex onto SBA-15 and reached a TOF of 25 in the same reaction. Moghadam et al. [50] have reported a TOF of 55.4 for the catalytic epoxidation of cis-cyclooctene with TBHP by a molybdenum complex supported onto multi-walled carbon nanotubes. All of these reports have lower TOF values than the TOF value obtained for Mo-AFBNPs in the present research work. In addition, the TOF values for Mo-AFBNPs and V-AFBNPs (75 and $39 \mathrm{~h}^{-1}$, respectively) in the present report are significantly greater than their Schiff-base counterparts, Mo-IFBNPs and V-IFBNPs (44 and 29 $\mathrm{h}^{-1}$, respectively), in our previous report [42].

\section{Conclusions}

We successfully prepared a new hybrid heterogeneous catalyst by anchoring the oxo-sulfate vanadium (IV) and hexacarbonyl molybdenum complexes onto the surface of AFBNPs. These are active catalysts for the epoxidation of various substituted alkenes under entirely heterogeneous conditions. Many molybdenum and vanadium Schiff base complexes have been reported for the catalytic epoxidation of alkenes with TBHP. However, the catalytic systems prepared in this work are superior to most of the reported catalytic protocols in terms of cost, reaction time, selectivity, conversion, TOF, and reusability. In addition, 20 -fold scale-up experiments confirmed the industrial application of these catalytic protocols. There are some crucial factors that considerably change the yields. Among them, the type of solvent is the most predominant, and $\mathrm{CCl}_{4}$ as an aprotic, non-polar, and hydrophobic solvent gave the best results.

\section{Acknowledgments}

The authors would like to thank the vice-president's office for research affairs of Shahrood University of Technology for the financial support of this work. We also would like to acknowledge the kind helps of Ms. Adonis Amoli and Mr. Mahmood Norouzi.

\section{References}

[1] L. Y. Hu, B. Yue, C. Wang, X. Y. Chen, H. Y. He, Appl. Catal. A, 2014, $477,141-146$.

[2] S. Huber, M. Cokoja, F. E. Kühn, J. Organomet. Chem., 2014, 751, 25-32.

[3] D. K. Dumbre, V. R. Choudhary, N. S. Patil, B. S. Uphade, S. K. Bhargava, J. Colloid Interface Sci., 2014, 415, 111-116.

[4] A. Held, J. Kowalska-Kus, A. Lapinski, K. Nowinska, J. Catal., 2013, $306,1-10$.

[5] B. Tyagi, U. Sharma, R. V. Jasra, Appl. Catal. A, 2011, 408, 171-177.

[6] Y. H. Li, X. S. Sun, J. Am. Oil Chem., 2014, 91, 1425-1432.

[7] H. Vrubel, K. J. Ciuffi, G. P. Ricci, F. S. Nunes, S. Nakagaki, Appl. Catal. A, 2009, 368, 139-145.

[8] H. R. Zhang, H. J. Yang, H. J. Guo, J. Yang, L. Xiong, C. Huang, X. P. Chen, L. L. Ma, Y. Chen, Appl. Clay Sci., 2014, 90, 175-180.

[9] S. T. Anuar, Y. Y. Zhao, S. M. Mugo, J. M. Curtis, J. Am. Oil Chem. Soc., 2012, 89, 1951-1960.

[10] Y. Guo, J. H. Hardesty, V. M. Mannari, J. L. Massingill Jr., J. Am. Oil Chem. Soc., 2007, 84, 929-935.

[11] M. A. de Luca, M. Martinelli, C. C. T. Barbieri, Prog. Org. Coat., 2009, 65, 375-380.

[12] A. Campanella, E. Rustoy, A. Baldessari, M. A. Baltanas, Bioresour. Technol., 2010, 101, 245-254.

[13] M. Amini, M. M. Haghdoost, M. Bagherzadeh, Coord. Chem. Rev., 2014, 268, 83-100.

[14] J. A. L. da Silva, J. J. R. F. da Silva, A. J. L. Pombeiro, Coord. Chem. Rev., 2011, 255, 2232- 2248.

[15] S. Rayati, F. Ashouri, Comptes Redus Chim., 2012, 15, 679-687.

[16] M. Sutradhar, L. M. D. R. S. Martins, M. F. C. Guedes da Silva, A. J. L. Pombeiro, Coord. Chem. Rev., 2015, 301-302, 200-239.

[17] R. Mbeleck, K. Ambroziak, B. Saha, D. C. Sherrington, React. Polym., 2007, 67, 1448-1457. 


\title{
Graphical Abstract
}

Chin. J. Catal., 2016, 37: 1263-1274 doi: 10.1016/S1872-2067(16)62451-8

\section{Amine-functionalized boehmite nanoparticle-supported molybdenum and vanadium complexes: Efficient catalysts for epoxidation of alkenes}

Mahdi Mirzaee*, Bahram Bahramian, Marieh Mirebrahimi Shahrood University of Technology, Iran

Boehmite nanoparticles with a high surface area and surface hydroxyl groups were covalently functionalized using 3-(trimethoxysilyl)-propylamine to support the vanadium-oxo-sulfate and molybdenum hexacarbonyl complexes, showing superior catalytic activity for the epoxidation of cis-cyclooctene.

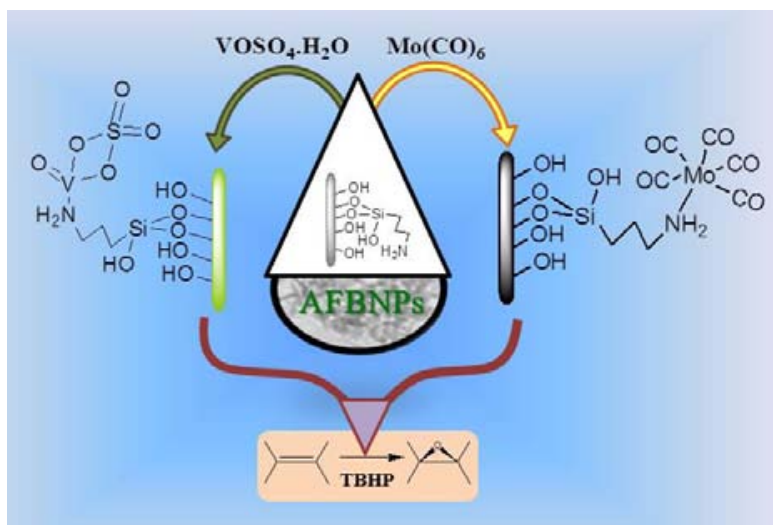

[18] G. Grivani, S. Tangestaninejad, A. Halili, Inorg. Chem. Commun., 2007, 10, 914-917.

[19] M. L. Mohammed, R. Mbeleck, B. Saha, Polym. Chem., 2015, 6, 7308-7319.

[20] S. Velusamy, M. Ahamed, T. Punniyamurthy, Org. Lett., 2004, 6, 4821-4824.

[21] W. Z. Fan, D. Y. Shi, B. N. Feng, Catal. Commun., 2016, 74, 1-4.

[22] U. Arnold, F. Fan, W. Habicht, M. Doring, J. Catal., 2007, 245, 55-64.

[23] Z. F. Li, S. J. Wu, D. F. Zheng, H. Liu, J. Hu, H. L. Su, J. Sun, X. Wang, Q. S. Huo, J. Q. Guan, Q. B. Kan, Appl. Catal. A, 2014, 470, 104-114.

[24] F. Esnaashari, M. Moghadam, V. Mirkhani, Sh. Tangestaninejad, I. Mohammadpoor-Baltork, A. R. Khosoropour, M. Zakeri, S. Hushmandrad, Polyhedron, 2012, 48, 212-220.

[25] X. F. Wang, S. J. Wu, Z. F. Li, X. Y. Yang, H. L. Su, J. Hu, Q. S. Huo, J. Q. Guan, Q. B. Kan, Microporous Mesoporous Mater., 2016, 221, 58-66.

[26] P. C. Bakala, E. Briot, L. Salles, J. M. Bregeault, Appl. Catal. A, 2006, 300, 91-99.

[27] C. I. Fernandes, M. S. Saraiva, T. G. Nunes, P. D. Vaz, C. D. Nunes, J. Catal., 2014, 309, 21-32.

[28] F. Bigi, C. G. Piscopo, G. Predieri, G. Sartori, R. Scotti, R. Zanoni, R. Maggi, J. Mol. Catal. A, 2014, 386, 108-113.

[29] A. Sakthivel, J. Zhao, G. Raudaschl-Sieber, M. Hanzlik, A. S. T. Chiang, F. E. Kuhn, Appl. Catal. A, 2005, 281, 267-273.

[30] M. Bagherzadeh, M. Zare, T. Salemnoush, S. Özkar, S. Akbayrak, Appl. Catal. A, 2014, 475, 55-62.

[31] T. Baskaran, R. Kumaravel, J. Christopher, T. G. Ajithkumar, A. Sakthivel, New J. Chem., 2015, 39, 3758-3764.

[32] J. Handzlik, J. Ogonowski, J. Stoch, M. Mikołajczyk, Catal. Lett., 2005, 101, 65-69.

[33] M. Farias, M. Martinelli, G. K. Rolim, Appl. Catal. A, 2011, 403, 119-127.
[34] M. Zare, Z. Moradi-Shoeili, M. Bagherzadeh, S. Akbayrak, S. Ozkar, New J. Chem., 2016, 40, 1580-1586.

[35] D. Zhou, B. Tang, X. H. Lu, X. L. Wei, K. Li, Q. H. Xia, Catal. Commun., 2014, 45, 124-128.

[36] M. Moosavifar, S. Tangestaninejad, M. Moghadam, V. Mirkhani, I. Mohammadpoor-Baltork, J. Mol. Catal. A, 2013, 377, 92- 101.

[37] G. Xu, Q. H. Xia, X. H. Lu, Q. Zhang, H. J. Zhan, J. Mol. Catal. A, 2007, 266, 180-187.

[38] K. Mahmoodi, B. Alinejad, Powder Technol, 2010, 199, 289-292.

[39] M. Trueba, S. P. Trasatti, Eur. J. Inorg. Chem., 2005, 3393-3403.

[40] A. Keivanloo, M. Bakherad, E. Imanifar, M. Mirzaee, Appl. Catal A, 2013, 467, 291-300.

[41] V. R. Choudhary, N. S. Patil, N. K. Chaudhari, S. K. Bhargava, J. Mol. Catal. A, 2005, 227, 217-222.

[42] M. Mirzaee, B. Bahramian, A. Amoli, Appl. Organometal. Chem., 2015, 29, 593-600.

[43] D. Bradley, R. C. Mehrotra, I. Rothwell, A. Singh, Alkoxo and Aryloxo Derivatives of Metals, Academic Press, London, 2001.

[44] M. M. Amini, M. Mirzaee, J. Sol-Gel Sci. Technol., 2005, 36, 19-23.

[45] B. Cornils, W. A. Hermann, Applied Homogeneous Catalysis with Organometallic Compounds, Wiley, Weinheim, 1996, 412-416.

[46] U. Neuenschwander, I. Hermans, J. Org. Chem., 2011, 76, 10236-10240.

[47] J. Sobczak, J. J. Ziolkowski, J. Less-Common Met., 1977, 54, 149-157.

[48] M. Mohammadikish, M. Masteri-Farahani, S. Mahdavi, J. Magn. Magn. Mater., 2014, 354, 317-323.

[49] Y. Yang, S. J. Hao, Y. Zhang, Q. B. Kan, Solid State Sci., 2011, 13, 1938-1942.

[50] M. Moghadam, S. Tangestaninejad, V. Mirkhani, I. Mohammadpoor-Baltork, N. S. Mirbagheri, J. Organomet. Chem., 2010, 695, 2014-2021.

\section{胺功能化的拟薄水铝石纳米颗粒负载的 Mn-V复合物：高效的烯烃环氧化催化剂}

\author{
Mahdi Mirzaee *, Bahram Bahramian, MariehMirebrahimi
}

沙赫鲁德科技大学化学系, 沙赫鲁德, 伊朗 
摘要: 将具有高比表面积和表面高度羟基化的拟薄水铝石纳米颗粒与3-(3甲氧基硅烷)-正丙胺进行共价结合而官能团化, 再用于负载硫酸氧钒和六羰基钿络合物。所得样品采用红外光谱、粉末 X射线衍射、热重-差热分析、X射线光电子能谱、 元素分析、电感耦合等离子体和透射电镜等技术进行了表征, 并用于顺-环辛烯的环氧化反应中, 优化了诸如溶剂和氧化剂 等反应条件. 反应过程采用气-液色谱进行监测. 重复使用实验表明, 该纳米催化剂可重复使用多次, 并保持顺-环辛烯接近 完全环氧化. 所得到的优化反应条件也成功用于其它的取代烯烃的环氧化反应中.

关键词: 拟薄水铝石纳米颗粒; 多相催化剂; 六羰基钼; 硫酸氧钒; 环氧化

收稿日期: 2016-03-26. 接受日期: 2016-04-30. 出版日期: 2016-08-05.

*通讯联系人. 电话/传真：+98-23-32395441; 电子信箱: mmirzaee@shahroodut.ac.ir

本文的英文电子版由Elsevier出版社在ScienceDirect上出版(http://www.sciencedirect.com/science/journal/18722067). 